\title{
B-TFIID Subunit Gene
}

National Cancer Institute

\section{Source}

National Cancer Institute. B-TFIID Subunit Gene. NCI Thesaurus. Code C20602.

Initiation of transcription by RNA polymerase II requires the assistance of TATA boxbinding protein (TBP) and TBP-associated factors, or TAFs, in 2 distinct complexes, TFIID and B-TFIID. The majority of TBP is present in the B-TFIID complex, which is composed of TBP and BTAF1. Stable association of TBP and BTAF1 requires the presence of DNA. BTAF1 inhibits TBP-driven RNA polymerase II and III transcription by driving the dissociation of TBP from DNA and freeing the TBP to associate with other TATA boxes or TATA-less promoters. (from OMIM 605191, LocusID 9044) 